\title{
Clinical outcomes and rates of aortic growth and reoperation after 1-stage repair of extensive chronic thoracic aortic dissection
}

\author{
Nicholas T. Kouchoukos, MD, ${ }^{\mathrm{a}}$ Alexander Kulik, MD, MPH, ${ }^{\mathrm{b}}$ and Catherine F. Castner, $\mathrm{BSN}^{\mathrm{a}}$
}

\section{ABSTRACT}

Objective: The study objective was to analyze clinical outcomes, distal segmental aortic growth, and aortic reoperation rates after 1-stage open repair of extensive chronic thoracic aortic dissection via bilateral anterior thoracotomy.

Methods: Eighty patients underwent extensive 1-stage repair of chronic aortic dissection that included the ascending aorta, the entire aortic arch, and the varying lengths of the descending thoracic aorta. One half or more of the descending thoracic aorta was replaced in $62(78 \%)$ of the 80 patients. Hospital mortality was $2.5 \%$ ( 2 patients). Stroke occurred in 1 patient $(1.2 \%)$, spinal cord ischemic injury occurred in 1 patient $(1.2 \%)$, and renal failure requiring long-term dialysis occurred in 2 patients $(2.5 \%)$. Sixty-five of the 78 hospital survivors $(83 \%)$ had serial imaging studies suitable for calculation of growth rates of the remaining dissected thoracic and abdominal aorta. Forty-seven patients were followed for more than 5 years, and 21 patients were followed for more than 10 years.

Results: The mean annual growth rate for the distal contiguous aorta was $1.7 \mathrm{~mm} / \mathrm{y}$. Forty aortas increased in diameter, 16 aortas remained unchanged, and 9 aortas decreased in diameter. Five patients required reoperation on the contiguous thoracic or abdominal aorta 8, 27, 34, 51, and 174 months postoperatively for progressive enlargement. Actuarial freedom from reoperation on the contiguous aorta at 5 and 10 years was $95.4 \%$ and 93\%, respectively. Actuarial freedom from any aortic reoperation at 5 and 10 years was $89.2 \%$ and $84.4 \%$, respectively. Actuarial survival for the entire cohort at 5 and 10 years was $76.4 \%$ and $52.6 \%$, respectively, and survival free of any aortic operation was $68.6 \%$ and $43.9 \%$, respectively. No patient whose cause of death was known died of aortic rupture.

Conclusions: Our extended experience with the 1-stage open procedure confirms its safety and durability for treatment of chronic aortic dissection with enlargement confined to the thoracic aorta. The procedure is associated with low operative risk and a low incidence of reoperation on the contiguous aorta. It represents a suitable alternative to the 2-stage, frozen elephant trunk, and hybrid procedures that are also used to treat this condition. (J Thorac Cardiovasc Surg 2018;155:1926-35)

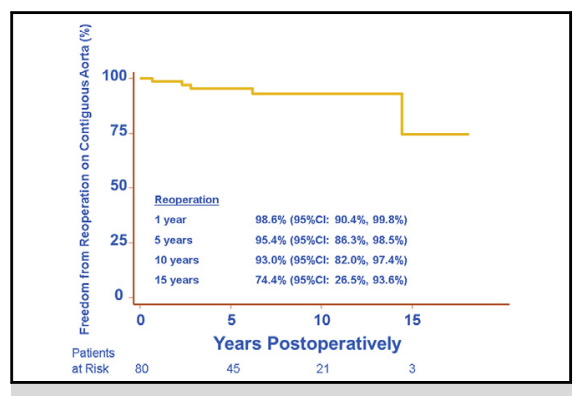

Freedom from reoperation on the contiguous distal aorta.

\section{Central Message}

The 1-stage open surgical procedure for repair of chronic extensive thoracic aortic dissection is a safe and durable procedure and a suitable alternative to the other open surgical options.

\section{Perspective}

Our extended experience with the 1-stage open procedure for repair of chronic extensive thoracic aortic dissection demonstrates a low operation risk and low incidence of reoperation on the contiguous distal aorta with follow-up extending to 18 years. It represents a safe and suitable alternative to 2-stage, frozen elephant trunk, and hybrid procedures that are also used to treat this condition.

See Editorial Commentary page 1936.

See Editorial page 1923.
From the ${ }^{\mathrm{a}}$ Division of Cardiovascular and Thoracic Surgery, Missouri Baptist Medical Center, BJC Healthcare, St Louis, Mo; and ${ }^{\mathrm{b}}$ Division of Cardiothoracic Surgery, Lynn Heart and Vascular Institute, Boca Raton Regional Hospital, and Charles E. Schmidt College of Medicine, Florida Atlantic University, Boca Raton, Fla.

Read at the 97th Annual Meeting of The American Association for Thoracic Surgery, Boston, Massachusetts, April 29-May 3, 2017.

Received for publication April 5, 2017; revisions received Oct 12, 2017; accepted for publication Oct 27, 2017; available ahead of print Feb 21, 2018.

Address for reprints: Nicholas T. Kouchoukos, MD, Missouri Baptist Medical Center, 3009 N. Ballas Rd, Suite 360C, St Louis, MO 63131 (E-mail: ntkouch@ aol.com). 0022-5223/\$36.00

Copyright (c) 2018 by The American Association for Thoracic Surgery

https://doi.org/10.1016/j.jtcvs.2017.10.158
Progressive dilation of the thoracic aorta after successful repair of acute type A aortic dissection is not uncommon, and up to $25 \%$ to $30 \%$ of patients will undergo an operation

Scanning this $\mathrm{QR}$ code will take you to a supplemental video. To view the AATS Annual Meeting Webcast, see the URL next to the webcast thumbnail. 


\section{Abbreviation and Acronym \\ $\mathrm{DTA}=$ descending thoracic aorta}

on the remaining dissected aorta in the 5 to 10 years after initial repair. ${ }^{1-4}$ Unrecognized type A aortic dissection can occur spontaneously or after operations on the coronary arteries and aortic valves, resulting in aneurysmal dilatation of the dissected thoracic aorta that requires surgical treatment. ${ }^{5,6}$ Retrograde dissection and enlargement of the aortic arch and ascending aorta can also occur in patients who sustain a type B aortic dissection and in patients after endovascular stent-graft repair of the thoracic aorta. ${ }^{7-9}$

The optimal method of surgical repair for patients who develop substantial enlargement of the remaining ascending aorta, aortic arch, and descending thoracic aorta (DTA) after acute dissection has not been clearly established. Options for management include staged procedures, commonly using the elephant trunk technique (conventional or frozen), hybrid procedures using endovascular grafts to exclude the aneurysmal thoracic aortic segments, and 1-stage procedures.

Concerns with all of these techniques include the fate of the dissected aorta distal to the DTA graft and the need for further interventions on this aortic segment. Since January of 1995 , we have used the 1-stage technique exclusively for patients with chronic extensive thoracic aortic dissection, and we present our experience, focusing on the clinical outcomes and on the rates of distal aortic enlargement and reoperation.

\section{PATIENTS AND METHODS}

During a 21-year interval ending in December, 2015, 80 patients with chronic, extensive aortic dissection and aneurysmal enlargement confined to the thoracic aorta underwent 1-stage resection and graft replacement of the ascending aorta, the aortic arch, and varying lengths of the DTA. Seventy-three patients had type A dissection, and 7 patients had type B dissection with proximal extension. This study was reviewed by the Institutional Review Board of the Missouri Baptist Medical Center and was exempt from Board Approval. The indications for 1-stage repair and the preoperative studies performed have been reported. ${ }^{10}$ All patients undergoing elective operation underwent preoperative cardiac catheterization and assessment of pulmonary function by a pulmonologist. No patient was denied operation because of severe pulmonary dysfunction. This decision was based on the premise that a 1-stage procedure would be less detrimental to pulmonary function than separate median sternotomy and left thoracotomy incisions that would be required for a 2-stage approach. Assessment of renal function and carotid artery disease, as well as other diagnostic studies, was performed when indicated. During the study interval, no other technique was used for repair of aneurysmal dilatation of a chronically dissected aorta that was confined to the thorax. Patients in whom the aneurysmal enlargement extended into the abdominal aorta were treated with staged procedures.

\section{Operative Technique}

Our current operative technique has been reported (see Video 1). ${ }^{10,11}$ In brief, it involves use of a bilateral anterior thoracotomy through the fourth intercostal space, transverse sternotomy, peripheral venous cannulation through the right common femoral vein using a 2-stage cannula with the tip positioned in the superior vena cava, and cannulation of the right common femoral artery and the right axillary artery. A branched aortic graft is used, sequentially attaching the 3 adjacent branches end-to-end to the 3 brachiocephalic arteries. ${ }^{11}$ This was accomplished in the most recent 54 patients during a brief (mean, $12.1 \pm 6.7$ minutes) interval of hypothermic circulatory arrest, followed by an interval of hypothermic $\left(20^{\circ} \mathrm{C}-22^{\circ} \mathrm{C}\right)$ brain perfusion through the right axillary artery (mean $41.1 \pm 12.3$ minutes) after clamp occlusion of the brachiocephalic arteries. ${ }^{12}$ After the interval of circulatory arrest, flow to the lower body is established from the femoral artery after placement of a clamp on the DTA. Cerebral oxygen saturation is continuously monitored using the Invos Cerebral Oximeter (Somanetics Corp, Troy, Mich).

After completion of the arch anastomoses and evacuation of air, the aortic graft proximal and distal to the branch grafts is occluded, and flow to the upper body is established from the right axillary artery. The site for attachment of the distal end of the graft to the DTA is determined. This is generally where the diameter of the remaining dissected aorta does not exceed 3.5 to $4.5 \mathrm{~cm}$ (mean measured diameter, $3.9 \pm 1.2 \mathrm{~cm}$ ). In larger patients, a diameter of up to $5 \mathrm{~cm}$ was considered suitable for attachment of the graft. Flow from the femoral artery is discontinued, and the clamp on the DTA is removed. A segment of the septum between the true and false lumens of the distal aorta is excised to permit perfusion of both channels, and the graft is sutured to the aorta, reinforcing the suture line with a strip of polytetrafluoroethylene felt. Patent intercostal arteries above the seventh intercostal space are ligated. If the aorta is divided below this level, the distal aorta is beveled when feasible to preserve the intercostal arteries. After this anastomosis is completed and air is evacuated from the graft, flow to the lower body is established in the antegrade direction from the axillary artery, and rewarming is initiated.

During rewarming, aortic valve or aortic root replacement and coronary artery bypass grafting are performed if indicated. The proximal end of the aortic graft is sutured to the ascending aorta at the level of the aortic commissures to an existing aortic graft or to a newly inserted composite graft. Coronary artery bypass grafts, if present, are anastomosed to the aortic

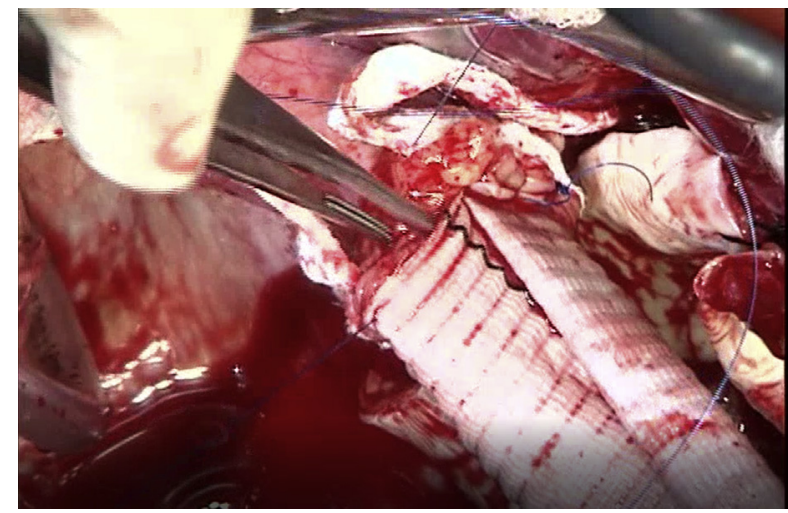

VIDEO 1. One-stage repair of a large aneurysm of the ascending aorta arch and DTA using a bilateral anterior thoracotomy (clamshell) incision through the fourth intercostal space, with left axillary, left femoral artery, and left femoral vein cannulation. Unilateral left axillary artery perfusion was used for brain protection after a brief (12 minutes) interval of hypothermic circulatory arrest. Video available at: http://www.jtcvsonline.org/ article/S0022-5223(17)33065-9/fulltext. 
graft. The durations of cardiopulmonary bypass and aortic occlusion were $201.7 \pm 52.9$ minutes and $143.4 \pm 46.3$ minutes, respectively.

\section{Extent of Resection and Concomitant Procedures}

The remaining ascending aorta, the entire aortic arch, and varying lengths of the DTA were resected and replaced in all patients. The extent of DTA replacement and the concomitant procedures performed are shown in Table 1.

\section{Follow-up}

The mean duration of clinical follow-up was 6.6 years and extended to 18.2 years. Serial computed tomography scans or magnetic resonance angiographic studies were obtained on hospital survivors 4 to 6 months postoperatively and at yearly intervals thereafter. Sixty-five of the 78 hospital survivors ( $83 \%$ ) had serial imaging studies suitable for calculation of growth rates of the remaining dissected DTA and abdominal aorta. Follow-up information was available for all patients and was current to October 2016.

\section{Radiographic Analysis}

The initial postoperative and final angiographic images were used to calculate changes in aortic diameter in the remaining DTA or at the level of the aortic hiatus if all of the DTA was replaced. The largest short-axis diameter of the outer contour of the affected aortic segment was measured. ${ }^{13}$ The annual growth rate was calculated as the difference in maximal diameter between the initial and final measurements divided by the time interval. All imaging studies were reviewed by at least 1 radiologist and 1 surgeon (N.T.K. or A.K.). The mean and median durations of angiographic follow-up were 6.2 and 5.8 years, respectfully, and follow-up extended to 18.2 years. Forty-seven patients were followed for more than 5 years and 21 patients for more than 10 years.

\section{Statistical Analyses}

Standard descriptive statistical analyses were used. Continuous data are presented as means \pm standard deviation. Categoric data are presented as proportions. Nonparametric estimates of freedom from all-cause death and reoperation were determined by using the Kaplan-Meier method and are reported as means. Data were analyzed in Intercooled Stata 9.2 software (Stata Corp, College Station, Tex).

\section{RESULTS}

\section{Patient Characteristics}

The baseline characteristics of the 80 patients are shown in Table 2. The mean patient age was 57 years

TABLE 1. Extent of descending thoracic aortic replacement and concomitant procedures

\begin{tabular}{lc}
\hline \multicolumn{1}{c}{ Operative details } & No. of patients \\
\hline Extent of descending thoracic aortic & \\
replacement & 18 \\
Proximal 1/3 & 53 \\
Proximal 1/2-3/4 & 9 \\
All & \\
Concomitant procedures & 21 \\
Aortic valve replacement & 9 \\
Aortic root replacement & 6 \\
Coronary artery bypass grafting & 1 \\
Mitral valve replacement & 2 \\
Partial lung resection & \\
\hline
\end{tabular}

TABLE 2. Baseline characteristics of the 80 patients

\begin{tabular}{lccc}
\multicolumn{1}{c}{ Variable } & \multicolumn{1}{c}{$\begin{array}{c}\text { No. of } \\
\text { patients }\end{array}$} & $\%$ \\
\hline Age (y) & $57 \pm 14.7$ & & \\
Male sex & & 58 & 72 \\
Connective tissue disorder & 10 & 13 & 16 \\
$\quad$ Marfan syndrome & 1 & & \\
$\quad$ Marfan + Loeys-Dietz syndrome & 1 & & \\
$\quad$ Loeys-Dietz syndrome & 1 & & \\
$\quad$ Loeys-Dietz + Ehlers-Danlos type 1 & & & \\
Dissection type & & 73 & 91 \\
$\quad$ Stanford A & & 7 & 9 \\
$\quad$ Stanford B & & & \\
Distal extent of dissection & & 8 & 10 \\
$\quad$ Descending thoracic aorta & & 72 & 90 \\
$\quad$ Abdominal aorta & & 61 & 76 \\
Previous aortic repair & & 71 & 89 \\
\hline Previous sternotomy & & & \\
\hline
\end{tabular}

(range, $22-81$ years), and $72 \%$ were men. Sixty-one patients had undergone previous repair of an acute type A aortic dissection. A type A dissection occurred in an additional 10 patients during or after valve replacement/ repair or coronary artery bypass grafting. Seven patients had type B dissection with proximal extension into the aortic arch and ascending aorta that was initially managed with medical therapy. The remaining 2 patients had chronic type A dissections that were initially managed without operation. Thirteen patients $(16 \%)$ had genetically mediated connective tissue disorders: 10 with Marfan syndrome, 1 with Marfan syndrome and Loeys-Dietz syndrome, 1 with Loeys-Dietz syndrome, and 1 with Loeys-Dietz syndrome and Ehlers-Danlos syndrome type 1 .

Among the 71 patients undergoing reoperation, the mean interval between the initial and the 1-stage procedures was 62.5 months (range, 1.7-265 months). At the time of the 1 -stage operation, the dissection extended into the abdominal aorta in 72 of the 80 patients.

\section{Early Mortality}

The hospital and 30-day mortality rates were 2.5\% (2 patients). A 71-year-old woman with an expanding chronic type A dissection and severe aortic regurgitation after a coronary artery bypass grafting procedure died in the operating room of biventricular failure. A 47-year-old man died on postoperative day 8 after a cardiac arrest. He had repair of an acute type A dissection 9 months previously and required reoperation for severe persisting aortic regurgitation and heart failure combined with progressive enlargement of the aortic arch and DTA. The 1-year mortality rate was $12 \%$ (8 patients). 
TABLE 3. In-hospital morbidity

\begin{tabular}{lcc}
\hline \multicolumn{1}{c}{ Complication } & No. of patients & $\%$ \\
\hline Reoperation for bleeding & 6 & 7.5 \\
\hline Stroke* & 1 & 1.2 \\
\hline Spinal cord ischemic injury (paraplegia) & 1 & 1.2 \\
\hline Temporary neurologic dysfunction & 11 & 14 \\
\hline Renal failure (dialysis) $\dagger$ & 6 & 7.5 \\
\hline Ventilatory support $>72 \mathrm{~h}$ & 34 & 42.5 \\
\hline Tracheostomy $\ddagger$ & 12 & 15 \\
\hline Deep wound infection & 1 & 1.2 \\
\hline Left recurrent nerve injury & 2 & 2.5 \\
\hline
\end{tabular}

*No neurologic deficit (diagnosis by computed tomography). †Two patients were discharged on dialysis. $\ddagger$ Nine patients were discharged with a tracheostomy.

\section{In-Hospital Morbidity}

The major postoperative complications are shown in Table 3. Six patients $(7.5 \%)$ required reoperation for bleeding. Stroke occurred in 1 patient $(1.2 \%)$, and spinal cord ischemic injury (paraplegia) occurred in 1 patient $(1.2 \%)$. Renal failure requiring dialysis occurred in 6 patients $(7.5 \%)$, and 2 of the 6 patients were receiving dialysis at the time of hospital discharge. Twelve patients $(15 \%)$ required a tracheostomy, and 9 of these patients had the tracheostomy in place at the time of discharge. One patient developed a deep chest wound infection that was managed conservatively. The mean intraoperative transfusion requirements were $8 \pm 5.1$ units of packed red blood cells, $6.3 \pm 3.9$ units of fresh-frozen plasma, $4.6 \pm 3$ units of platelets, and $10.8 \pm 18$ units of cryoprecipitate. The mean duration of the postoperative stay was 20.5 days (median, 11; range, 6-71 days).

\section{Growth of the Distal Aorta}

The mean annual growth rate for the entire cohort was $1.7 \mathrm{~mm} / \mathrm{y}$. The maximum aortic diameter increased in 40 patients (mean, $2.8 \mathrm{~mm} / \mathrm{y}$ ), remained unchanged in 16 patients, and decreased in 9 patients (mean, $-0.6 \mathrm{~mm} / \mathrm{y}$ ) (Table 4). The growth rate was highest for the 12 patients

TABLE 4. Growth rates of the distal aorta after 1-stage repair of chronic thoracic aortic dissection

\begin{tabular}{|c|c|c|c|}
\hline Variable & & $\begin{array}{c}\text { No. of } \\
\text { patients }\end{array}$ & $\begin{array}{c}\text { Growth } \\
\text { rate } \mathrm{mm} / \mathrm{y}\end{array}$ \\
\hline All imaged aortas & & 65 & 1.7 \\
\hline With increase in diameter & 40 & & 2.8 \\
\hline With no change in diameter & 16 & & \\
\hline With decrease in diameter & 9 & & -0.6 \\
\hline \multicolumn{4}{|c|}{ Distal aortic diameter at time of operation } \\
\hline$\geq 4.5 \mathrm{~cm}$ & & 12 & 2.5 \\
\hline$<3.0 \mathrm{~cm}$ & & 5 & 0.4 \\
\hline \multicolumn{4}{|l|}{ Extent of distal dissection } \\
\hline Descending thoracic aorta & & 8 & -0.2 \\
\hline Abdominal aorta & & 57 & 1.9 \\
\hline
\end{tabular}

whose initial aortic diameters were $4.5 \mathrm{~cm}$ or greater $(2.5 \mathrm{~mm} / \mathrm{y})$ and lowest for the 5 patients whose initial aortic diameter was $3 \mathrm{~cm}$ or less $(0.4 \mathrm{~mm} / \mathrm{y})$. The annual growth rate for the 8 patients in whom the dissection was confined to the thoracic aorta was $-0.2 \mathrm{~mm} / \mathrm{y}$ and $1.9 \mathrm{~mm} / \mathrm{y}$ for the 57 patients in whom the dissection extended into the abdominal aorta (Table 4).

\section{Reoperations}

Contiguous aorta. Five patients required reoperation on the contiguous thoracic or abdominal aorta distal to the aortic graft for aneurysmal degeneration at 8, 27, 34, 51, and 174 months postoperatively. Four of the 5 patients had replacement of the remaining thoracic aorta and the abdominal aorta to a level just above the aortic bifurcation. Separate branch grafts were placed to the renal and visceral arteries. The fifth patient was a Jehovah's Witness and underwent a hybrid procedure with separate grafts to the renal and visceral arteries originating from an abdominal aortic bifurcation graft, followed by placement of an endovascular stent graft into the thoracic and abdominal aorta. The patient who required reoperation at 8 months had Loeys-Dietz and type I Ehlers-Danlos syndromes. She underwent the 1-stage procedure 4 months after repair of an acute type A dissection. The aortic growth rates for the 5 patients ranged from $2 \mathrm{~mm} / \mathrm{y}$ to $18.6 \mathrm{~mm} / \mathrm{y}$. All 5 patients survived the reoperation. No patient whose dissection was confined to the DTA has required reoperation. Actuarial freedom from reoperation for aneurysmal growth of the contiguous distal aorta at 5 and 10 years was $95.4 \%$ and 93\%. respectively (Figure 1).

One patient, a 77-year-old woman, had evidence for progressive growth of the aorta from $5.1 \mathrm{~cm}$ at the time of the one-stage procedure to $6.0 \mathrm{~cm} 6$ years later. Reoperation

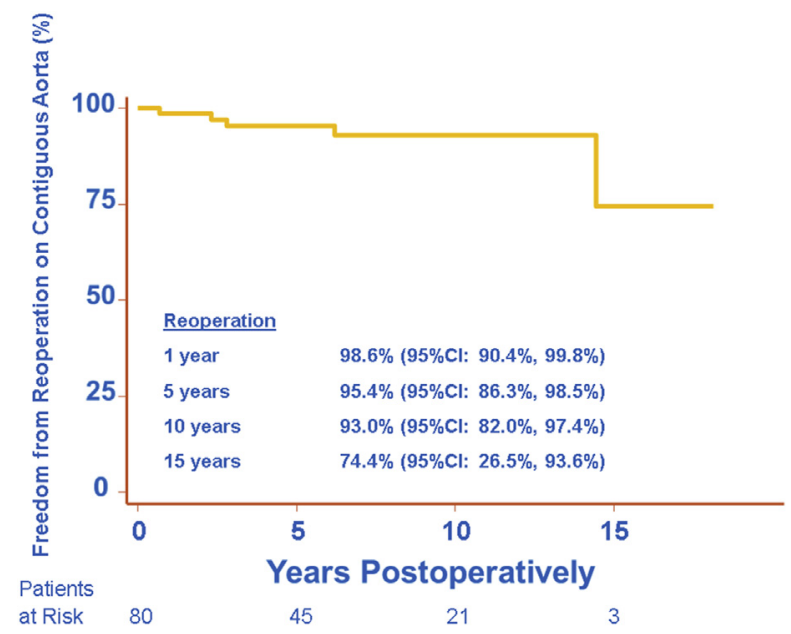

FIGURE 1. Freedom from reoperation on the contiguous distal aorta for aneurysmal degeneration after the 1-stage surgical procedure. CI, Confidence interval. 


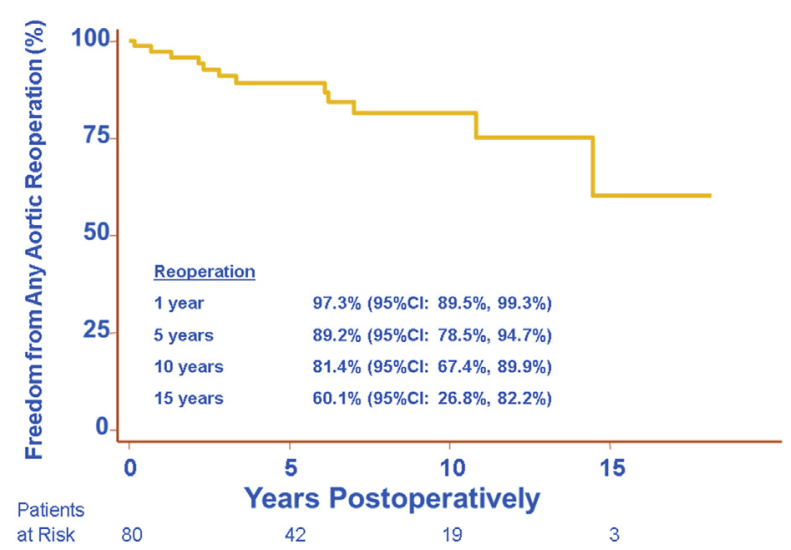

FIGURE 2. Freedom from any aortic reoperation after the 1-stage surgical procedure. $C I$, Confidence interval.

was not advised because of her age and the absence of symptoms. She died of sepsis at 85 years of age.

Seven additional patients required operations on the aorta or its major branches, on the aortic graft, or the aortic valve for indications unrelated to aneurysmal growth of the contiguous aorta. Three patients required reoperation for repair of a false aneurysm at the proximal (2) or distal (1) suture line of the aortic graft, 1 for a false aneurysm of the aortic graft due to erosion, 2 for aortic valve regurgitation, and for infrarenal abdominal and iliac artery aneurysms. Six of the 7 patients survived reoperation. Actuarial freedom from any aortic reoperation was $89.2 \%$ at 5 years and $81.4 \%$ at 10 years (Figure 2).

\section{Late Mortality}

During the follow-up interval, which extends to 18.2 years, there have been 42 late deaths. The modes of death are shown in Table 5. No patient whose cause of death was known died of aortic rupture. Angiographic follow-up was available for 4 of the 6 patients whose cause of death

TABLE 5. Mode of late deaths

\begin{tabular}{lc}
\hline \multicolumn{1}{c}{ Cause } & No. of patients \\
\hline Cardiac failure & 9 \\
Cancer & 5 \\
\hline Sepsis & 4 \\
Multiple organ failure & 3 \\
\hline Intracranial aneurysm/hemorrhage & 3 \\
Stroke & 4 \\
Respiratory failure & 3 \\
Renal failure & 1 \\
\hline Intestinal infarction & 1 \\
Postoperative hemorrhage & 1 \\
Sudden & 2 \\
Unknown & 6 \\
\hline
\end{tabular}

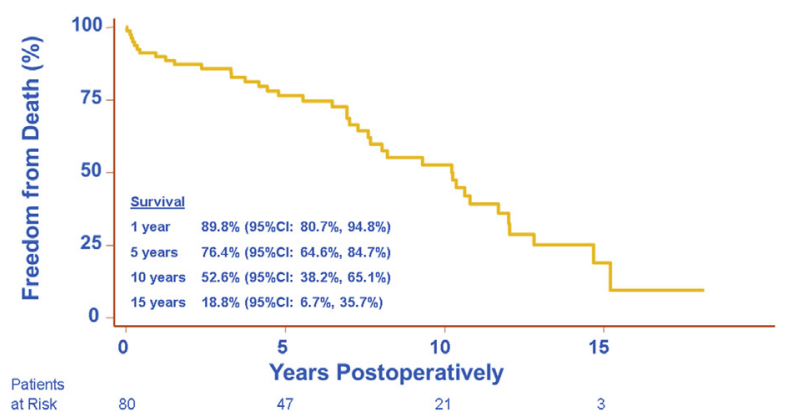

FIGURE 3. Long-term survival after the 1-stage surgical procedure. $C I$, Confidence interval.

was unknown. None of these 4 patients had evidence for rapid aortic growth, and all were followed for more than 7 years. The remaining 2 patients whose cause of death was unknown had angiographic follow-up for 5 years and 6 years, respectively, without evidence for significant aortic growth. Of the total group, 47 patients have been followed for more than 5 years and 21 patients have been followed for more than 10 years. Actuarial survival for the entire cohort at 5 and 10 years was $76.4 \%$ and $52.6 \%$, respectively (Figure 3), and survival free of aortic reoperation at 5 and 10 years was $68.6 \%$ and $43.9 \%$, respectively (Figure 4 ).

\section{DISCUSSION}

Our extended experience with the 1-stage procedure confirms that it is a safe and suitable option for treatment of chronic aortic dissection with aneurysmal degeneration confined to the thoracic aorta. The early mortality $(2.5 \%)$ does not exceed that reported for the first stage of the conventional elephant trunk procedure, although among several large published series and a single meta-analysis, patients with chronic dissection were not analyzed separately. ${ }^{14-18}$ Among patients with chronic dissection treated with the frozen elephant technique, early mortality in the 4 largest reported series has ranged from $1.1 \%$ to $15.5 \%{ }^{19-22}$ Sun and colleagues ${ }^{19}$ reported an early

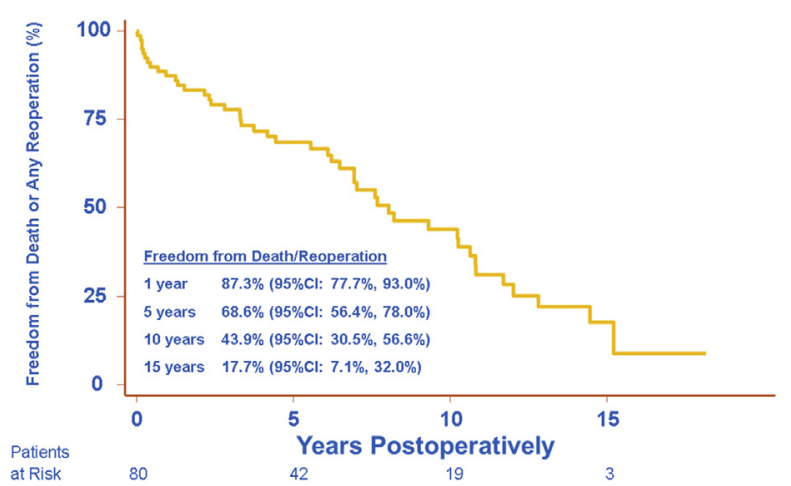

FIGURE 4. Freedom from death or any reoperation. $C I$, Confidence interval. 


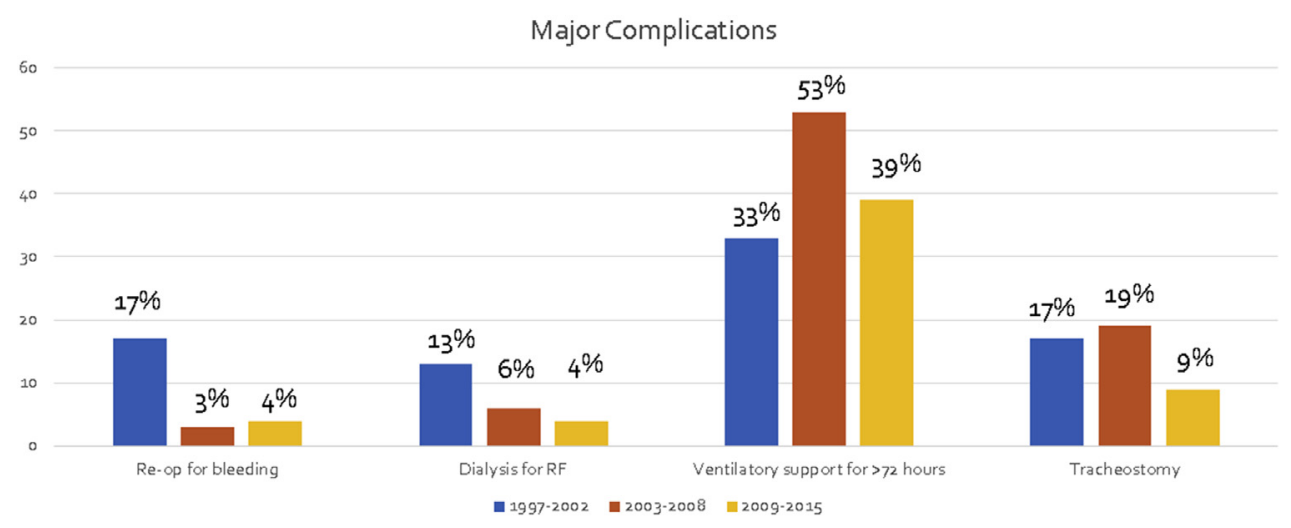

FIGURE 5. Prevalence of major complications according to date of operation. $R F$, Renal failure.

mortality rate of $1.1 \%$ for 89 patients. However, patients with aneurysms measuring $5 \mathrm{~cm}$ or greater were excluded from the frozen elephant trunk procedure in this study. In the remaining 3 series, early mortality ranged from $10.2 \%$ to $15.5 \%{ }^{20-22}$ In the published series of patients undergoing hybrid debranching procedures involving the aortic arch, where patients with chronic aortic dissection were analyzed separately, the early mortality for this subset ranged from $3 \%$ to $17 \%$. $^{23-25}$

With regard to postoperative morbidity, the prevalence of stroke and renal failure requiring dialysis in the present study did not exceed that reported from the series of patients undergoing the frozen elephant trunk procedure $(2.2 \%$ to $9.8 \%$ and $12 \%$ to $22 \%$, respectively), ${ }^{19-22}$ or the hybrid procedure (3\% to $8 \%$ and $0 \%$ to $11 \%$, respectively). ${ }^{23-25}$ The relatively high prevalence of pulmonary dysfunction in our series of patients, as evidenced by the need for prolonged intubation and tracheostomy, has been considered to be a limitation of the 1-stage procedure. ${ }^{19,26,27}$ However, the frequency of these complications with the alternative procedures has not been thoroughly documented. Among patients undergoing the conventional 2-stage elephant trunk procedure, the prevalence of tracheostomy was reported in only 1 series and was $16.5 \%$ for the 2 procedures. ${ }^{15}$ In our series of 1 -stage procedures, it was $15 \%$. Among patients undergoing the frozen elephant trunk procedure, the frequency of prolonged intubation for more than 72 hours was documented in only 2 of the series and was $12 \%$ and $24 \% .^{20,22}$ No data regarding the prevalence of tracheostomy were provided. No data regarding the need for prolonged intubation or tracheostomy were provided for patients undergoing hybrid procedures. In our series, with increasing experience, the prevalence of major complications including tracheostomy has been gradually reduced (Figure 5). The only exception has been the need for prolonged intubation. With regard to other complications, it is important to note that the prevalence of spinal cord ischemic injury among patients undergoing the frozen elephant trunk procedure ranged from $2.2 \%$ to $10.9 \%{ }^{19-22}$ and that retrograde aortic dissection occurred in 3 of 90 patients undergoing the hybrid procedure, one of which was fatal. ${ }^{23-25}$

The fate of the distal aorta and the need for subsequent aortic interventions are important considerations for the management of patients after extensive thoracic aortic repair. Our study has shown a variable but low overall rate of growth of the aorta distal to the aortic graft $(1.7 \mathrm{~mm} / \mathrm{y})$. With follow-up extending to 18 years, growth occurred in 40 of the 65 patients at a mean rate of $2.8 \mathrm{~mm} / \mathrm{y}$. In the remaining 25 patients, the aortic diameter distal to the graft remained unchanged or decreased slightly (Table 4). Although the growth rate was highest for the 12 patients with the largest aortic diameters $(\geq 4.5 \mathrm{~cm})$, only 2 of these patients required reoperation on the contiguous aorta. No aortic growth was observed among the 8 patients in whom the dissection was confined to the thoracic aorta. This group included 3 patients with Marfan syndrome. The rates of aortic growth for the 5 patients requiring reoperation on the contiguous aorta were variable, ranging from 0.2 to $1.9 \mathrm{~mm} / \mathrm{y}$, and the initial aortic diameter of the remaining dissected aorta after the 1-stage procedure ranged from 3 to $5 \mathrm{~cm}$. The reoperative procedures were performed between 8 and 174 months after the index operation. These findings indicate that continued surveillance for aortic growth is essential for all patients, irrespective of the initial diameter of the remaining aorta.

For patients in whom the conventional elephant trunk procedure is used to treat patients with extensive chronic thoracic aortic dissection, a second open or endovascular procedure is almost always required. In addition to the early mortality associated with the 2 procedures, there is an interval mortality that has been noted in every published series, and a proportion of these deaths were due to aortic rupture. Among the series of patients undergoing the frozen elephant trunk procedure for chronic dissection, Sun and colleagues $^{19}$ reported 1 subsequent intervention for open repair of a thoracoabdominal aortic aneurysm among 89 
patients during a mean follow-up interval of 28.5 months. ${ }^{19}$ As noted previously, patients with aneurysms greater than $5 \mathrm{~cm}$ were excluded. In the study of Di Eusanio and colleagues, $^{20} 11$ of 49 patients $(22 \%)$ required an endovascular intervention on the distal aorta during a mean follow-up interval of 13 months. In an earlier report of the multicenter EVITA Open stent graft trial than the one of Leontyev and colleagues, ${ }^{21}$ in which late follow-up was available for patients with chronic dissection, freedom from endovascular repair of the distal aorta was $69 \%$ at 4 years. ${ }^{28}$ One additional patient required open repair. For patients undergoing hybrid procedures, 3 of 12 patients with chronic dissection in the series of Cochennec and colleagues $^{23}$ required a subsequent intervention: one for occlusion of a carotid-to carotid bypass graft and 2 for additional stent grafts to correct type III endoleaks during a median follow-up of 13 months. In the largest series of patients with chronic aortic dissection treated with hybrid procedures, Faure and colleagues ${ }^{25}$ placed additional stent grafts in 6 of 33 patients $(18 \%)$ for type I and type II endoleaks during a mean follow-up interval of 2 years. Actuarial freedom from any reoperation was $53 \%$ at 2 years. In the aggregate, these findings indicate that, with the exception of the single study of Sun and colleagues, ${ }^{19}$ a substantial number of subsequent interventions on the graft or the distal aorta were required during the early postoperative interval.

Our extended follow-up of patients after the 1-stage procedure has demonstrated a low rate of reoperation on the contiguous downstream aorta (7\% at 10 years) and a low overall rate of growth of the distal aorta. These findings indicate that after replacement of the more proximal aneurysmal aortic segments using this technique, distal aneurysm formation is infrequent. Urbanski and colleagues $^{29}$ treated 17 patients with extensive chronic aortic dissection with arch replacement or arch and DTA replacement via a clamshell approach combined with distal resection of the dissection membrane to establish distal flow into both the true and false lumens. ${ }^{29}$ There were no early deaths and 1 late death due to leukemia. During the follow-up interval that extended to 118 months, no noticeable progression of the chronic dissection in the downstream aorta was documented in any patient.

Possible explanations for the low rates of growth and aneurysm formation after the 1-stage procedure include stabilization of the aorta at the distal anastomosis that results from firm fixation to the aortic graft and buttressing of the suture line with a felt strip, and maintenance of flow into both the true and false lumens. With stent grafting, fixation of the graft to the aortic wall is often incomplete and complete thrombosis of the false lumen surrounding the graft has not been consistently observed. The lack of fixation results in persistent pressurization of the false lumen surrounding the graft. It is a contributing factor to the need for subsequent interventions and remains as one of the important limitations of the technique.

\section{Study Limitations}

Our study is the largest to date to report outcomes associated with repair of chronic extensive thoracic aortic dissection using a 1-stage open technique. It involved retrospective review of prospectively collected data in a referral-based tertiary care center, and the results must be interpreted within the context of this study design. The procedures were performed on a single surgical service, and the results may not be generalizable to other surgical centers. Surgical techniques evolved over the duration of the study. Although follow-up imaging studies were not performed in all patients, data for analysis of distal aortic growth rate were available for $83 \%$ of the entire cohort of hospital survivors and for $93 \%$ of the 70 patients followed for more than 1 year. Overall mortality was $47.4 \%$ at 10 years, but was unrelated to the aortic disease.

It has not been clearly established that more extensive primary repair of acute type A aortic dissection that includes replacement of the aortic arch and proximal DTA will reduce the frequency of subsequent operations on the thoracic aorta, such as those described in this study. Until this hypothesis is substantiated, we continue to favor a more limited repair for the majority of patients with acute type A dissection that involves the ascending aorta and proximal aortic arch.

\section{CONCLUSIONS}

Our extended experience with the 1-stage open procedure confirms it safety and durability for treatment of chronic aortic dissection with enlargement confined to the thoracic aorta. The procedure is associated with low operative risk and a low incidence of reoperation on the contiguous distal aorta. The prevalence of spinal cord ischemic injury is less than that reported for the frozen elephant trunk and hybrid procedures. It represents a suitable alternative to the 2-stage, frozen elephant trunk and hybrid procedures that are also used to treat this condition. Because growth of the distal aorta occurs at a variable rate, lifelong surveillance of patients with chronic aortic dissection is required.

\section{Webcast}

You can watch a Webcast of this AATS meeting presentation by going to: https://aats.blob.core.windows.net/media/ 17AM/2017-05-02/BallroomABC/05-02-17_BallroomABC_ 1045_Kouchoukos.mp4.

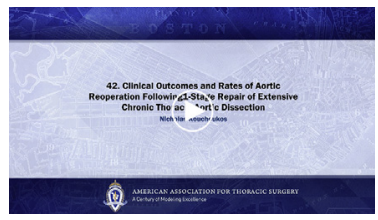




\section{Conflict of Interest Statement}

Authors have nothing to disclose with regard to commercial support.

\section{References}

1. Kazui T, Yamashita K, Washiyama N, Terada H, Bashar ABM, Suzuki T, et al. Impact of an aggressive surgical approach on surgical outcome in type A aortic dissection. Ann Thorac Surg. 2002;74:S1844-7.

2. Halstead JC, Meier M, Etz C, Spielvogel D, Bodian C, Wurm M, et al. The fate of the distal aorta after repair of acute type A aortic dissection. J Thorac Cardiovasc Surg. 2007; 133:127-35.

3. Zierer A, Voeller RK, Hill KE, Kouchoukos NT, Damiano RJ, Moon M. Aortic enlargement and late reoperation after repair of acute type A aortic dissection. Ann Thorac Surg. 2007;84:479-87.

4. Geirsson A, Bavaria JE, Swarr D, Keane MG, Woo YJ, Szeto WY, et al. Fate of the residual distal and proximal aorta after acute type A dissection repair using a contemporary surgical reconstruction algorithm. Ann Thorac Surg. 2007;84: 1955-64.

5. Still RJ, Hilgenberg AD, Akins CW, Daggett WM, Buckley MJ. Intraoperative aortic dissection. Ann Thorac Surg. 1992;53:374-9.

6. Gillinov AM, Lytle BW, Kaplon RJ, Casselman FP, Blackstone EH, Cosgrove DM. Dissection of the ascending aorta after previous cardiac surgery: differences in presentation and management. J Thorac Cardiovasc Surg. 1999; 117:252-60.

7. Canaud L, Ozdemir BA, Patterson BO, Holt PJ, Loftus IM, Thompson MM. Retrograde aortic dissection after thoracic endovascular aortic repair. Ann Surg. 2014;260:389-95.

8. Preventza O, Garcia A, Moeller K, Cooley DA, Gonzalez L, Cheong BY, et al. Retrograde ascending aortic dissection after thoracic endovascular aortic repair for distal aortic dissection or with zone 0 landing: association, risk factors, and true incidence. Ann Thorac Surg. 2015;100:509-15.

9. Higashigawa T, Kato N, Chino S, Hashimoto T, Shimpo H, Tokui T, et al. Type A aortic dissection after thoracic endovascular aortic repair. Ann Thorac Surg. 2016;102:1536-42.

10. Kouchoukos NT, Masetti P, Mauney MC, Murphy MC, Castner CF. Onestage repair of extensive chronic aortic dissection using the arch-first technique and bilateral anterior thoracotomy. Ann Thorac Surg. 2008;86: 1502-9.

11. Kouchoukos NT. One-stage repair of extensive thoracic aortic aneurysm using the arch-first technique and bilateral anterior thoracotomy. J Op Techs Cardiovasc Surg. 2009;12:220-31.

12. Kulik A, Castner CF, Kouchoukos NT. Outcomes after total aortic arch replacement with right axillary artery cannulation and a presewn multibranched graft. Ann Thorac Surg. 2011;92:889-97.

13. Hirose $Y$, Hamada $S$, Takamiya M, Imakita $S$, Naito $H$, Nishiyama $T$. Aortic aneurysms: growth rates measured with CT. Radiology. 1992;185: 249-52.

14. LeMairé SA, Carter SA, Coselli JS. The elephant trunk technique for staged repair of complex aneurysms of the entire thoracic aorta. Ann Thorac Surg. 2006;81:1561-9.

15. Etz CD, Plestis KA, Kari FA, Luehr M, Bodian CA, Spielvogal D, et al. Staged repair of thoracic and thoracoabdominal aortic aneurysms using the elephant trunk technique: a consecutive series of 215 first stage and 120 complete repairs. Eur J Cardiothorac Surg. 2008;34:605-15.

16. Svensson LG, Rushing GD, Balenzuela ES, Rafael AE, Batizy LH, Blacksone EH, et al. Modifications, classification, and outcomes of elephanttrunk procedures. Ann Thorac Surg. 2013;96:548-58.

17. Shrestha M, Martens A, Krüger H, Maeding I, Ius F, Fleissner F, et al. Total aortic arch replacement with the elephant trunk technique: single-center 30-year results. Eur J Cardiothorac Surg. 2014;45:289-96.

18. Ius F, Hagl C, Haverich A, Pichlmaier M. Elephant trunk procedure 27 years after Borst: what remains and what is new? Eur J Cardiothorac Surg. 2011; 40:1-12.

19. Sun LZ, Qi RD, Chang Q, Zhu JM, Liu YM, Yu CT, et al. Is total arch replacement combined with stented elephant trunk implantation justified for patients with chronic Stanford type A aortic dissection? J Thorac Cardiovasc Surg. 2009;138:892-6.

20. Di Eusanio M, Armaro A, Di Marco L, Pancini D, Savini C, Suarez SM, et al. Short-and midterm results after hybrid treatment of chronic aortic dissection with the frozen elephant trunk technique. Eur J Cardiothorac Surg. 2011;40:875-80.

21. Leontyev S, Tsagakis K, Pacini D, Di Bartolomeo R, Mohr FW, Weiss G et al. Impact of clinical factors and surgical techniques on early outcome of patients treated with frozen elephant trunk technique by using EVITA open stent-graft: results of a multicenter study. Eur J Cardiothorac Surg. 2016;49:660-6.

22. Weiss G, Tsagakis K, Jakob H, Di Bartolomeo R, Pacini D, Barberio G, et al. The frozen elephant trunk technique for the treatment of complicated type B aortic dissection with involvement of the aortic arch: multicenter early experience. Eur J Cardiothorac Surg. 2015;47:106-14.

23. Cochennec F, Tresson P, Cross J, Desgranges P, Allaire E, Becquemin JP. Hybric repair of aortic arch dissections. J Vasc Surg. 2013;57:1560-7.

24. Bünger CM, Kische S, Liebold A, Leißner M, Glass A, Schareck W, et al. Hybrid aortic arch repair for complicated type B aortic dissection. J Vasc Surg. 2013;58 1490-6.

25. Faure EM, Canaud L, Marty-Ané C, Alric P. Hybrid aortic arch repair for dissecting aneurysm. J Thorac Cardiovasc Surg. 2016;152:162-8.

26. Kazui T. Invited commentary. Ann Thorac Surg. 2008;86:1509.

27. Roselli EE, Sepulveda E, Pujara AC, Idrees J, Nowicki E. Distal landing zone open fenestration facilitates endovascular elephant trunk completion and false lumen thrombosis. Ann Thorac Surg. 2011;92:2078-84.

28. Pacini D, Tsagakis K, Jakob H, Mestres CA, Armaro A, Weiss G, et al. The frozen elephant trunk for the treatment of chronic dissection of the thoracic aorta: a multicenter experience. Ann Thorac Surg. 2011;92:1663-70.

29. Urbanski PP, Bougioukakis P, Deja MA, Diegeler A, Irimie V, Lenos A et al. Open aortic arch surgery in chronic dissection with visceral arteries originating from different lumens. Eur J Cardiothorac Surg. 2016;49: 1382-90.

Key Words: chronic aortic dissection, thoracic aorta, surgical repair, 1-stage procedure

\section{Discussion}

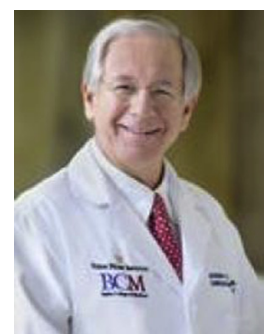

Dr J. Coselli (Houston, Tex). We have learned so much from Dr Kouchoukos over the years and from his careful study, clinical work, and major contributions to the field of aortic surgery. Kouchoukos and colleagues report on a series of 80 patients undergoing stage I proximal aortic and descending thoracic aortic repair via bilateral thoracotomy for extensive chronic thoracic aortic dissection. It is clearly one of the largest reports of its kind. The excellent results set a benchmark for evaluating the early results and the ability of other procedures, including staged repairs or the newest hybrid approaches. The durability of their repairs and the stability of the remaining aorta are well documented and remarkable, $95 \%$ at 5 years and $93 \%$ at 10 years. With follow-up to 15 years, they encountered no known deaths from aortic rupture, and their results provide a compelling argument for considering this approach, particularly in younger patients, given their documentation of a low need for reintervention and the elimination of the risk of interval rupture, of unrepaired aorta, as well as a second procedure. So I have a few simple questions, really.

I would like Dr Kouchoukos to enlighten us on his thoughts on the approach of cerebrospinal fluid drainage in such patients, the timing, volume, pressure, and duration. 


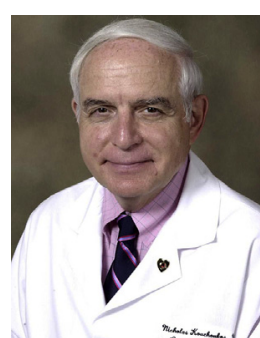

Dr N. Kouchoukos (St Louis, Mo). We did not use spinal drainage in any of these patients. We do use it for more extensive procedures on the descending thoracic and thoracoabdominal aorta. We use hypothermia as the main adjunct for spinal cord protection.

Dr Coselli. So please comment on your thoughts regarding your myocardial protection in this remarkable series.

Dr Kouchoukos. We use both antegrade and retrograde cardioplegia for myocardial protection in all of the patients.

Dr Coselli. What was your target core temperature during the period of systemic hypothermic circulatory arrest during the period of lower body perfusion, and have your temperature targets evolved over the years with attention more recently being paid to try to do some of these cases at warmer temperatures?

Dr Kouchoukos. When we began to use this procedure some 20 years ago, we were concerned about the duration of circulatory arrest, and we performed the arch anastomosis first to quickly reestablish blood flow to the brain, and then proceeded with the descending repair and finally, the ascending repair. In the last 54 patients, we have used axillary perfusion with an interval of circulatory arrest at $20^{\circ} \mathrm{C}$ for an average of 12 minutes. During this interval, we open the aortic arch, clamp the origins of the brachiocephalic arteries, and establish unilateral brain perfusion through the axillary artery. We then complete the arch and distal anastomoses, maintaining hypothermic perfusion at $20^{\circ} \mathrm{C}$. We then begin rewarming, gradually establish full flow, and complete the proximal anastomosis.

Dr Coselli. The article is a remarkable document with a plethora of important information and I recommend it to anyone interested in the field. Finally, you've evolved away from an island approach to the brachiocephalic vessels and moved more toward a branch approach. Considering that the results are really excellent in both in your report, why the change and what are your thoughts on that?

Dr Kouchoukos. I believe that the branch technique is easier to use. After the brachiocephalic arteries are occluded, they are attached sequentially to the branches of the graft beginning with the left subclavian and proceeding proximally. I believe it is much easier to identify and control troublesome bleeding with the branch technique.

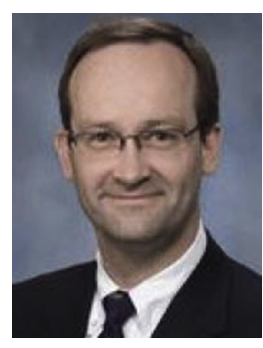

Dr T. Sundt (Boston, Mass). It used to be Sundt, St Louis, and when it was Sundt St Louis, I had the good fortune to be Dr Kouchoukos's student and then associate. I once again express to you how deeply indebted I am to you as a clinical mentor. I also have to make a confession, which is that I still like this operation. In fact, I like it so much that we showed a movie of it on Saturday, because not everyone has seen it, and I am convinced it still has an important place in our armamentarium. So when we brought on a new aortic surgeon at the Massachusetts General Hospital recently, we did 3 of them in the first month he was with us just to be sure that he had it in his toolbox as well!

I have 2 questions, 1 related to the Achilles heel of this operation, every operation has at least 1 weakness, and for this one I think it is bleeding given the extent of the procedure. I wonder what you have learned over the course of your experience with the procedure to reduce the need for reoperation for bleeding.

Dr Kouchoukos. The most troublesome cause of bleeding with this procedure comes from the intercostal arteries. When you are perfusing at low flow, you attempt to ligate all of the patent vessels. But all the bleeding sites may not be apparent at low flow. It is critically important after rewarming is completed and cardiopulmonary bypass has been discontinued to reexamine the intercostal arteries and ligate those that are still bleeding. This was the principal cause of our reoperations for bleeding.

Dr Sundt. I couldn't agree more. It took me a while to figure that out. I don't like Teflon felt in general, but I use pledgeted stitches for those intercostals, because they are hard to get at. If you use a trifurcated graft at the arch and then do the distal anastomosis with a separate graft, you can flow below and identify those vessels. So that is one of the things I have learned. I agree, it is really hard to see them at the end of the operation with the lungs going up and down and you are trying to push the graft out of the way.

The other weakness of this operation is in the postoperative period related to the ventilatory issues and the duration of ventilation. I wonder if you have got any comments about the use of epidural analgesia and such to reduce that ventilatory time.

Dr Kouchoukos. We have used it only occasionally. I believe the key to reducing the duration of mechanical ventilation is to avoid trauma to the left lung during the procedure, and this is not always easy. The lung is collapsed, and with full heparinization it is vulnerable to injury and intraparenchymal hemorrhage. I instruct our trainees and everyone else involved in these procedures to be careful and to avoid excessive manipulation of the left lung.

We have, over time, pressed for earlier extubation to minimize the duration of ventilation and the attendant complications with some success, but pulmonary complications still occur. 


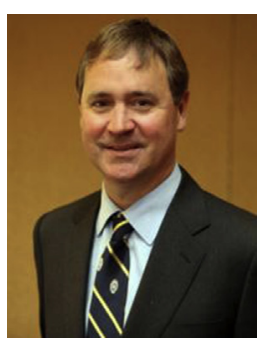

Dr M. Moon (St Louis, Mo). Dr Kouchoukos, I would like to ask a question maybe of you and Dr. Coselli. You have educated us over the years on the techniques that we can use to try to perform these complex procedures as safely as possible and reproducibly as possible. Aortic surgery is a complex field to get involved in, and I was wondering what motivated you to follow aortic surgery throughout your career. One of the focuses of this meeting has been about mentorship and teaching. Please give us any thoughts you might have on that along that way.

Dr Kouchoukos. I became interested in aortic surgery a long time ago. Along with the fellow who is at the other end of this podium, Stanley Crawford was an important mentor for me. I went and spent time with him when I was interested in the aorta, and he was incredibly helpful in terms of discussing cases, I could always call him and get some advice, and we proceeded from there. It has been an area of interest of mine for a long time, but we had some great mentors along the way. I think Joe would agree.

Dr Coselli. Yes, I would agree entirely. From my own experience having spent seven years training with Dr DeBakey's program and then joining Stanley Crawford, in the first part it was aorta half the time and after that it was aorta all the time. I would say this about you, though. Dr Crawford thought very highly of you, and actually within a month or so of his stroke, one of the last things he did was continuing, Thor, to learn, even at his age. And to do that effort, one of the things he did is went and visited Nick Kouchoukos to learn about the Ross operation at the time. So that is just a huge compliment to all the contributions you have made, even to our mentors as well as ourselves.

Readers who found these articles interesting may also like to read the following papers found in recent and future issues of our sister publications, Seminars in Thoracic and Cardiovascular Surgery and Operative Techniques in Thoracic and Cardiovascular Surgery!

\section{Adult: Aortic}

ORIGINAL SUBMISSION: Best Medical Treatment and Selective Stent-Graft Repair for Acute Type B Aortic Intramural Hematoma. Gabriele Piffaretti. Semin Thoracic Surg 2017: In press.

ORIGINAL SUBMISSION: Fluctuations in Spinal Cord Perfusion Pressure: a Harbinger of Delayed Paraplegia after Thoracoabdominal Aortic Repair. Harleen K. Sandhu. Semin Thoracic Surg 2017: 451-459.

Editorial Commentary: Keep Alert Eyes on Delayed Paraplegia. Kenji Minatoya. Semin Thoracic Surg 2017: 460-461.

Editorial Commentary: Problem Delayed Does Not Mean Solution Denied. Joseph S. Coselli. Semin Thoracic Surg 2017: 462-463.

ORIGINAL SUBMISSION: Awake Thoracic Endovascular Aneurysm Repair for Aortic Rupture: A Case Series. Jessica Forcillo. Semin Thoracic Surg 2017: In press.

Editorial Commentary: Awake TEVAR for Ruptured Thoracic Aneurysms: Less is More? Akiko Tanaka. Semin Thoracic Surg 2017: In press.

ORIGINAL SUBMISSION: Impact of Discordant Views in the Management of Descending Thoracic Aortic Aneurysm. Peter Chiu. Semin Thoracic Surg 2017: 283-291.

Editorial Commentary: Surgery Is in the Eye of the Beholder. Anthony L. Estrera. Semin Thoracic Surg 2017: 292-293. 